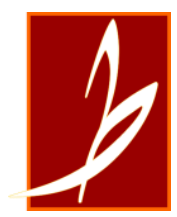

THUFULI: Jurnal Pendidikan Islam Anak Usia Dini

Volume 2 Nomor 1 Tahun 2020

e-ISSN: 2685-161X

\title{
PENERAPAN MEDIA GAMBAR UNTUK MENINGKATKAN KEMAMPUAN BERBICARA PADA ANAK KELOMPOK B DI KB PUTRA BANGSA
}

\author{
Dwi Imam Efendi, Erlin Nur Azizah \\ ${ }^{1}$ Universitas PGRI Ronggolawe, ${ }^{2}$ Universitas PGRI Ronggolawe \\ e-mail: $\underline{\text { xarsono.gas13@gmail.com }}$
}

\begin{tabular}{lcc}
\hline Diterima: 6 Juni 2020 & I Direvisi: 9 Juni 2020 & I Disetujui: 10 Juni 2020 \\
(C)2020 Pendidikan Guru Raudhatul Atfhal Fakultas Agama Islam Universitas Islam Malang
\end{tabular}

\begin{abstract}
This study aims to determine the extent to which the ability to speak through media images in the Play Group of the Putra Bangsa Desa. The research approach used is Classroom Action Research with qualitative and quantitative descriptive methods. The subjects of the study were 24 students in Group B consisting of 9 boys and 15 girls. The study was conducted in Group B at KB Putra Bangsa Ngemplak, Baureno District, Bojonegoro Regency, Academic Year 2018/2019. Data obtained through observation and documentation. The results of the study found an increase in the ability to speak through media images in group B in the Putra Bangsa Play Group Ngemplak Village, Baureno District, Bojonegoro Regency 2018/2019 Academic Year. This is evidenced by an increase in value by $92.7 \%$ of children able to speak fluently, 91.7\% of children are able to speak using clear articulation, 96.9\% of children are able to speak using complete sentences ( $\mathrm{S}-\mathrm{P}-\mathrm{O}-\mathrm{K})$.
\end{abstract}

Keywords: image media, speaking ability, playgroup

\section{A. Pendahuluan}

Menurut Patmonodewo dalam Suyanto (2005) mengatakan bahwa bentuk Pendidikan yang menitikberatkan pada fondasi dasar yang berupa beberapa aspek perkembangan diantaranya kecerdasan spiritual, perkembangan fisik motoric, social emosional. Komunikasi dan Bahasa, serta koginitif merupakan sebuah pendifinisian dari Pendidikan anak usia dini. Bahasa merupakan salah satu perkembangan yang dipelajari pada anak usia dini. Bahasa dapat digunakan sebagai alat komunkasi dengan cara menafsirkan pikiran dan perasaan, tujuannya adalah untuk menyampaikan makna kepada orang lain (Hurlock, 1987).

Salah satu bagian dari Bahasa adalah berbicara. Berbicara merupakan keterampilan. Keterampilan berbicara adalah sesuatu yang dikembangkan mulai dari anak usia dini yang berhubungan dengan perkembangan kosa kata yang dimiliki oleh anak (Jalongo, 200).

This work is licensed under Creative Commons Attribution Non Commercial 4.0 International License Available online on: http://riset.unisma.ac.id/index.php/fai/index 
Media menurut Dadan (2006) merupakan salah satu alat yang digunakan sebagai saluran dalam meyemapaikan informasi atau pesan dari sumber bicara kepada penerima besan bicara. Menurut Sadiman (2009) dalam media merupakan sesuatu yang dapat menstimulasi perasaan, pikiran, minat dan perhatian yang bertujuan untuk meningkatkan prestasi belajar siswa.

Pada kenyataannya di KB Putra Bangsa Desa Ngemplak banyak anak yang masih belum mau berbicara dengan baik dan benar itu terbukti dari setiap guru memberikan suatu pertanyaan kepada anak, anak masih belum mau menjawab. Mungkin anak masih belum terlalu lancar dalam berbicara. Atau metode yang di gunakan oleh guru kurang menarik sehingga anak tidak termotivasi dan aktivitas belajarnya masih kurang.

Sangatlah penting bagi kita sebagai wali murid atau guru untuk mengajarkan sedini mungkin di anak untuk bisa bicara dengan lancar, dan jelas (Wahyuni, 2016). Supaya tidak ada hambatan atau gangguan di dalam berkomunikasi sehari-hari. Untuk itu di upayakan pembelajaran berbicara hendaknya di laksanakan dengan aktif, menarik, dan penuh kreasi bagi anak. Supaya anak merasa senang dan bisa mencapai apa yang di ingkannya. Langkah yang dapat di ambil yaitu dengan membantu anak didik mengenal dan melatih berbicara dan mengajak orang tua ikut serta melatih berbicara secara benar. Agar anak memiliki motivasi berbicara dengan benar dan berani untuk menjadi anak yang kreatif.

Berbicara adalah kemampuan mengucap bunyi/bahasa untuk mengekspresikan atau menyampaikan pikiran,gagasan atau keinginan secara lisan (Poerwadaminta, 2003). Adapun faktor yang mempengaruhi kemampuan anak dalam berbicara yaitu tidak bisa mengucapkan apa yang dia tau atau yang inginkan. Dan dalam pengembangan berbicara anak usia dini tentu melewati proses yang tidak mudah dan membutuhkan waktu yang tidak sebentar, sehingga agar masa masa tersebut dapat di lewati dengan baik dan mudah (Isnaini, 2019).

Media gambar merupakan alat berbentuk gambar alam sekitar dianatranya seperti tumbuhan hijau kering, binatang air laut udara dan benda-benda yang ada dalam kehidupan keseharian anak (Sadiman, 2009). Menurut Ihtiar (2015) mengungkapkan bahwa media dapat diklasifikasikan berdasarkan pengalaman selama belajar anak yaitu mulai dari pengalaman yang bersifat konkret sampai yang bersifat abstrak.

Dari semua uraian diatas diharapkan melalui media gambar pada Kelompok Bermain Putra Bangsa Desa Ngemplak Kecamatan Baureno Kabupaten Bojonegoro dapat meningkatkan kemampuan anak dalam berbicara, selain itu diharapkan dapat meningkatkan semangat anak dalam proses belajar di Kelompok 
Bermain Putra Bangsa Desa Ngemplak Kecamatan Baureno Kabupaten Bojonegoro

\section{B. METODE}

Metode penelitian ini menggunakan metode deskriptif kualitatif dan kuantitatif. Tujuan yang ingin dicapai dalam penelitian ini yaitu untuk mengetahui sebesar mana kemampuan berbicara melalui media gambar pada Kelompok Bermain Putra Bangsa Desa Ngemplak Kecamatan Baureno Kabupaten Bojonegoro Tahun Pelajaran 2018/2019. Subjek penelitian yang diambil dalam penelitian tindakan kelas ini adalah siswa Kelompok B yang berjumlah 24 anak yang terdiri dari 9 anak laki-laki dan 15 anak perempuan.

Tabel 1 Data Nama-Nama Anak

\begin{tabular}{|c|l|c|}
\hline No & \multicolumn{1}{|c|}{ Nama Anak } & Jenis Kelamin \\
\hline 1 & Alfian & L \\
\hline 2 & Bima & L \\
\hline 3 & Erlino & L \\
\hline 4 & Mega & P \\
\hline 5 & Putri & L \\
\hline 6 & Ahmad & L \\
\hline 7 & Rizky & L \\
\hline 8 & Darian & P \\
\hline 9 & Elok P & P \\
\hline 10 & Cantika s & L \\
\hline 11 & Fadlan & P \\
\hline 12 & Salsa & P \\
\hline 13 & Lathifah & L \\
\hline 14 & Wisnu & P \\
\hline 15 & Yumna & P \\
\hline 16 & Keyla & P \\
\hline 17 & Natsya & P \\
\hline 18 & Rinda & P \\
\hline 19 & Salsabila & L \\
\hline 20 & Zero & L \\
\hline 21 & Ibrahim & P \\
\hline 22 & Desi & P \\
\hline 23 & Elina & P \\
\hline 24 & Claudia & \\
\hline
\end{tabular}


Teknik pengemumpulan data yang digunakan adalah teknik non tes meliputi observasi dan dokumentasi. Tahapan dalam penelitian ini adalah perencanaan, Pelaksanaan Tindakan, Observasi, Refleksi I. Analisis data dalam penelitian ini adalah data-data yang diperoleh dari hasil lembar observasi dan dokumentasi mengenai hasil pembelajaran kemampuan berbicara melalui bermain peran. Analisis dilakukan pada setiap siklus dengan teknik deskriptif kuantitatif.

Analisis data dalam penelitian ini adalah data-data yang diperoleh dari hasil lembar observasi dan dokumentasi mengenai hasil pembelajaran berbicara melalui metode bermain peran. Analisis dilakukan pada setiap siklus dengan teknik deskriptif kuantitatif. Adapun rumus yang digunakan untuk mencari persentase dalam penelitian ini adalah sebagai berikut:

$$
\text { Prosentase }=\frac{\text { Nilai Yang Diperoleh }}{\text { Skor Maksimal Ideal }} \times 100 \%
$$

Sudjiono (2005) menyatakan data tersebut diinterprestasikan ke dalam persentase sebagai berikut :

1. Kriteria baik, yaitu apabila hasil penilaian kemampuan berbicara yang diperoleh anak antara 76-100\%.

2. Kriteria cukup, yaitu apabila hasil penilaian kemampuan berbicara yang diperoleh anak antara 56-75\%.

3. Kriteria kurang, yaitu apabila hasil penilaian yang diperoleh anak antara 41$55 \%$.

4. Kriteria belum baik, yaitu apabila hasil penilaian yang diperoleh anak antara 0$40 \%$.

\section{HASIL DAN PEMBAHASAN}

Penelitian dilakukan di Kelompok Bermain Putra Bangsa Desa Ngemplak yang beralamat di Desa Ngemplak Kecamatan Baureno Kabupaten Bojonegoro. Kelompok Bermain Putra Bangsa Desa Ngemplak merupakan keanggotaan HIMPAUDI Baureno. Kelompok Bermain Putra Bangsa Desa Ngemplak berada dalam situasi yang kondusif, karena lokasi sekolah tidak berada di depan jalan raya, sehingga aman bagi anak-anak. Akses menuju jalan rayapun tidak terlalu jauh.

Pembelajaran di Kelompok Bermain Putra Bangsa Desa Ngemplak menggunakan model pembelajaran kurikulum 2013. Kelompok Bermain Putra Bangsa Desa Ngemplak dipimpin oleh dua guru, 1 guru yang menjabat sebagai kepala sekolah 1 guru sebagai membantu kelancaran administrasi dan keamanan 
di sekolah. Sarana dan prasarana sudah memadai dan diatur sedemikian rupa menyesuaikan kondisi halaman sekolah yang tidak begitu luas, khususnya permainan outdoor.

\section{PRA SIKLUS}

Hasil prasiklus yang bertujuan mengetahui bagaimanakah kemampuan berbicara melalui metode media gambar pada Kelompok Bermain Putra Bangsa Desa Ngemplak Kecamatan Baureno Kabupaten Bojonegoro Tahun Pelajaran 2018/2019.

Tabel 2 Hasil PRA SIKLUS

\begin{tabular}{|c|l|c|c|c|}
\hline \multirow{2}{*}{ No } & \multirow{2}{*}{ Nama Anak } & \multirow{2}{*}{ Prosentase } & \multicolumn{2}{|c|}{ Ket } \\
\hline & & & T & TT \\
\hline 1 & Alfian & 41,7 & & \\
\hline 2 & Bima & 33,3 & & $\checkmark$ \\
\hline 3 & Erlino & 41,7 & & $\checkmark$ \\
\hline 4 & Mega & 50,0 & & $\checkmark$ \\
\hline 5 & Putri & 50,0 & & $\checkmark$ \\
\hline 6 & Ahmad & 33,3 & & $\checkmark$ \\
\hline 7 & Rizky & 41,7 & & $\checkmark$ \\
\hline 8 & Darian & 41,7 & & $\checkmark$ \\
\hline 9 & Elok P & 33,3 & & $\checkmark$ \\
\hline 10 & Cantika s & 33,3 & & $\checkmark$ \\
\hline 11 & Fadlan & 50,0 & & $\checkmark$ \\
\hline 12 & Salsa & 41,7 & & $\checkmark$ \\
\hline 13 & Lathifah & 33,3 & & $\checkmark$ \\
\hline 14 & Wisnu & 41,7 & & $\checkmark$ \\
\hline 15 & Yumna & 41,7 & & $\checkmark$ \\
\hline 16 & Keyla & 58,3 & & $\checkmark$ \\
\hline 17 & Natsya & 41,7 & & $\checkmark$ \\
\hline 18 & Rinda & 41,7 & & $\checkmark$ \\
\hline 19 & Salsabila & 33,3 & & $\checkmark$ \\
\hline 20 & Zero & 50,0 & & $\checkmark$ \\
\hline 21 & Ibrahim & 33,3 & & $\checkmark$ \\
\hline 22 & Desi & 41,7 & & $\checkmark$ \\
\hline 23 & Elina & 41,7 & & $\checkmark$ \\
\hline 24 & Claudia & 58,3 & \\
\hline & & & $\checkmark$ \\
\hline
\end{tabular}


Dari data observasi kemampuan berbicara sebelum dilakukan tindakan menunjukkan bahwa kemampuan berbicara belum baik. Dilihat dari tabel tersebut menyatakan bahwa belum ada anak yang tuntas hal ini menunjukkan hanya 40,6\% anak mampu berbicara lancar, $42,7 \%$ anak mampu berbicara menggunakan artikulasi yang jelas, 42,7\% anak mampu Berbicara menggunakan kalimat yang lengkap (S-P-O-K).

\section{SIKLUS I}

Hasil silkus satu yang memiiliki tujuan mengetahui bagaimanakah kemampuan berbicara melalui metode media gambar pada Kelompok Bermain Putra Bangsa Desa Ngemplak Kecamatan Baureno Kabupaten Bojonegoro Tahun Pelajaran 2018/2019.

Tabel 3 Hasil SIKLUS I

\begin{tabular}{|c|l|c|l|l|}
\hline \multirow{2}{*}{ No } & \multirow{2}{*}{ Nama Anak } & \multirow{2}{*}{ Prosentase } & \multicolumn{2}{|c|}{ Ket } \\
\hline & & & T & TT \\
\hline 1 & Alfian & 75,0 & $\checkmark$ & \\
\hline 2 & Bima & 83,3 & $\checkmark$ & \\
\hline 3 & Erlino & 75,0 & $\checkmark$ & \\
\hline 4 & Mega & 83,3 & $\checkmark$ & \\
\hline 5 & Putri & 58,3 & & $\checkmark$ \\
\hline 6 & Ahmad & 83,3 & $\checkmark$ & \\
\hline 7 & Rizky & 58,3 & & $\checkmark$ \\
\hline 8 & Darian & 91,7 & $\checkmark$ & \\
\hline 9 & Elok P & 66,7 & & \\
\hline 10 & Cantika s & 75,0 & $\checkmark$ & \\
\hline 11 & Fadlan & 83,3 & $\checkmark$ & \\
\hline 12 & Salsa & 91,7 & $\checkmark$ & \\
\hline 13 & Lathifah & 50,0 & & $\checkmark$ \\
\hline 14 & Wisnu & 75,0 & $\checkmark$ & \\
\hline 15 & Yumna & 83,3 & $\checkmark$ & \\
\hline 16 & Keyla & 66,7 & & $\checkmark$ \\
\hline 17 & Natsya & 83,3 & $\checkmark$ & \\
\hline 18 & Rinda & 75,0 & $\checkmark$ & \\
\hline 19 & Salsabila & 91,7 & $\checkmark$ & \\
\hline 20 & Zero & 83,3 & $\checkmark$ & \\
\hline
\end{tabular}




\begin{tabular}{|l|l|c|l|l|}
\hline \multirow{2}{*}{ No } & \multirow{2}{*}{ Nama Anak } & \multirow{2}{*}{ Prosentase } & \multicolumn{2}{|c|}{ Ket } \\
\hline & & & T & TT \\
\hline 21 & Ibrahim & 75,0 & $\checkmark$ & \\
\hline 22 & Desi & 83,3 & $\checkmark$ & \\
\hline 23 & Elina & 66,7 & & $\checkmark$ \\
\hline 24 & Claudia & 83,3 & $\checkmark$ & \\
\hline
\end{tabular}

Berdasarkan tabel 4.2 tersebut dapat diungkapkan bahwa hasil persentase pencapaian kemampuan berbicara anak pada siklus I menunjukkan peningkatan. Hasil rata-rata persentase pencapaian sesudah siklus I diperoleh data sebagai berikut : 75,0\% anak mampu berbicara lancar, 76,0\% anak mampu berbicara menggunakan artikulasi yang jelas, 79,2\% anak mampu berbicara menggunakan kalimat yang lengkap (S-P-O-K).

\section{SIKLUS II}

Untuk mengetahui adakah peningkatan kemampuan berbicara pada kelompok B di Kelompok Bermain Putra Bangsa Desa Ngemplak Kecamatan Baureno Kabupaten Bojonegoro Tahun Pelajaran 2018/2019.

Tabel 4 Hasil Peningkatan SIKLUS II

\begin{tabular}{|c|l|c|c|c|}
\hline \multirow{2}{*}{ No } & \multirow{2}{*}{ Nama Anak } & \multirow{2}{*}{ Prosentase } & \multicolumn{2}{|c|}{ Ket } \\
\cline { 4 - 5 } & & & T & TT \\
\hline 1 & Alfian & 100,0 & $\checkmark$ & \\
\hline 2 & Bima & 100,0 & $\checkmark$ & \\
\hline 3 & Erlino & 91,7 & $\checkmark$ & \\
\hline 4 & Mega & 91,7 & $\checkmark$ & \\
\hline 5 & Putri & 83,3 & $\checkmark$ & \\
\hline 6 & Ahmad & 91,7 & $\checkmark$ & \\
\hline 7 & Rizky & 100,0 & $\checkmark$ & \\
\hline 8 & Darian & 91,7 & $\checkmark$ & \\
\hline 9 & Elok P & 91,7 & $\checkmark$ & \\
\hline 10 & Cantika s & 83,3 & $\checkmark$ & \\
\hline 11 & Fadlan & 100,0 & $\checkmark$ & \\
\hline 12 & Salsa & 100,0 & $\checkmark$ & \\
\hline 13 & Lathifah & 91,7 & $\checkmark$ & \\
\hline 14 & Wisnu & 91,7 & $\checkmark$ & \\
\hline 15 & Yumna & 91,7 & $\checkmark$ & \\
\hline
\end{tabular}




\begin{tabular}{|c|l|c|c|c|}
\hline \multirow{2}{*}{ No } & \multirow{2}{*}{ Nama Anak } & \multirow{2}{*}{ Prosentase } & \multicolumn{2}{|c|}{ Ket } \\
\cline { 4 - 5 } & & & T & TT \\
\hline 16 & Keyla & 91,7 & $\checkmark$ & \\
\hline 17 & Natsya & 91,7 & $\checkmark$ & \\
\hline 18 & Rinda & 91,7 & $\checkmark$ & \\
\hline 19 & Salsabila & 100,0 & $\checkmark$ & \\
\hline 20 & Zero & 91,7 & $\checkmark$ & \\
\hline 21 & Ibrahim & 91,7 & $\checkmark$ & \\
\hline 22 & Desi & 91,7 & $\checkmark$ & \\
\hline 23 & Elina & 100,0 & $\checkmark$ & \\
\hline 24 & Claudia & 100,0 & $\checkmark$ & \\
\hline
\end{tabular}

Hasil belajar tabel 4.3 tersebut dapat diketahui bahwa, hasil persentase pencapaian kemampuan berbicara melalui media gambar pada Siklus II menunjukkan peningkatan pada setiap pertemuannya. Maka pengujian hipotesis sudah memenuhi standart yang diinginkan, oleh karena itu penelitian dihentikan pada siklus II. Refleksi setelah perbaikan pembelajaran siklus II selesai dilaksanakan, hasil belajar yang dicapai oleh anak terlihat daya serap anak yang meningkat.

Mengingat bahwa perbaikan pembelajaran siklus II dilaksanakan setelah peneliti meupun teman sejawat menemukan kelemahan pembelajaran yang berarti, dan melihat hasil yang dicapai anak sudah maksimal. Peneliti memberi pesan agar selalu berlatih dirumah agar kemampuan anak akan semakin bertambah baik.

Pada siklus II diperoleh data sebagai berikut : 92,7\% anak mampu berbicara lancar, 91,7\% anak mampu berbicara menggunakan artikulasi yang jelas, 96,9\% anak mampu berbicara menggunakan kalimat yang lengkap (S-P-O-K). Bahwa hasil peningkatan kemampuan berbicara anak pada Siklus II diketahui bahwa ada peningkatan kemampuan berbicara

Dari data tersebut diatas maka pengujian hipotesis sudah memenuhi standart yang diinginkan, oleh karena itu penelitian dihentikan pada siklus II. Refleksi setelah perbaikan pembelajaran siklus II selesai dilaksanakan, hasil belajar yang dicapai oleh anak terlihat daya serap anak yang meningkat. Berikut ini akan disajikan tabel Rekapitulasi Peningkatan Kemampuan Berbicara Melalui Metode Media gambar PRA SIKLUS, SIKLUS I, SIKLUS II 
Tabel 5. Rekapitulasi Peningkatan Kemampuan Berbicara Melalui Metode Media gambar PRA SIKLUS, SIKLUS I, SIKLUS II

\begin{tabular}{|c|c|c|c|c|}
\hline \multirow{2}{*}{ No } & \multirow{2}{*}{ Indikator } & \multicolumn{3}{|c|}{ Penilaian } \\
\cline { 3 - 5 } & & Pra Siklus & Siklus I & Siklus II \\
\hline 1 & $\mathrm{~A}$ & 40,6 & 75,0 & 92,7 \\
\hline 2 & $\mathrm{~B}$ & 42,7 & 76,0 & 91,7 \\
\hline 3 & $\mathrm{C}$ & 42,7 & 79,2 & 96,9 \\
\hline
\end{tabular}

Dari data diatas dapat disimpulkan bahwa dengan adanya kenaikan prosentase hasil belajar tersebut mengindikasikan bahwa penggunaan media gambar dapat meningkatkan kemampuan berbicara pada kelompok B di Kelompok Bermain Putra Bangsa Desa Ngemplak Kecamatan Baureno Kabupaten Bojonegoro Tahun Pelajaran 2018/2019.

\section{SIMPULAN}

Kemampuan berbicara melalui media gambar pada kelompok B di Kelompok Bermain Putra Bangsa Desa Ngemplak Kecamatan Baureno Kabupaten Bojonegoro Tahun Pelajaran 2018/2019, telah terjadi peningkatan hal ini dapat diketahui pada kegiatan yang sudah peneliti lakukan dari pra siklus pada tahun 2018/2019, mendapatkan kreteria cukup.

Kemampuan berbicara melalui media gambar pada kelompok B di Kelompok Bermain Putra Bangsa Desa Ngemplak Kecamatan Baureno Kabupaten Bojonegoro, dapat meningkatkan kemampuan berbicara dilihat dari observasi yang telah peneliti lakukan. Selain dapat meningkatkan kemampuan berbicara, dapat juga ,meningkatkan kemampuan kognitif dan sosisla emosional pada anak. Kegiatan yang dilaksanakan peneliti pada tahun pelajaran 2018/2019, mendapatkan kreteria baik.

Ada peningkatan kemampuan berbicara melalui media gambar pada kelompok B di Kelompok Bermain Putra Bangsa Desa Ngemplak Kecamatan Baureno Kabupaten Bojonegoro Tahun Pelajaran 2018/2019, berhasil meningkat terbukti pada nilai prosentase 92,7\% anak mampu berbicara lancar, 91,7\% anak mampu berbicara menggunakan artikulasi yang jelas, 96,9\% anak mampu berbicara menggunakan kalimat yang lengkap (S-P-O-K).

\section{DAFTAR RUJUKAN}

Djuanda, Dadan. (2006) Pembelajaran Bahasa Indonesia Yang Komunikatif dan Menyenangkan. Jakarta: Depdiknas. 
Efendi, Dwi Imam. (2019). Pengaruh Latihan Ladder Drill Terhadap Kelincahan Pada Anak Usia Dini Kelompok B di Taman Kanak-kanak Khoiriyatussibyan. Prosiding SNasPPM. Volume 4 No 1, 16-21

Hurlock, Elizabeth B. (1978). Perkembangan Anak Jilid 2. Jakarta: Erlangga.

Ihtiar, Citra. (2015). Peningkatan Keterampilan Menyimak Melalui Metode Bercerita Dengan Gambar Pada Anak Kelompok A Di TK PKK Gedongkiwo Mantrijeron Yogyakarta. Jurnal Pendidikan Guru PAUD. Volume 4 No 9.

Isnaini, Siti Nur Indah. (2019). Pelaksanaan Metode Bercakap-Cakap Dalam Pengembangan Keterampilan Bicara Anak Kelompok B. 1 Di RA Permata Belia Kalipancur Semarang Tahun Pelajaran 2017/2018. Skripsi. Semarang: UIN Walisongo.

Jalongo, Mary Renck (2000). Early Childhood Language Arts: Meeting Diverse Literacy Needs through Collaboration with Families and Professionals. United State: Allin Bacon.

Poerwadarminta, W J S. (2003). Kamus Umum Bahasa Indonesia. Jakarta: Balai Pustaka.

Riyanto, Arifah A.(2002). Teori Busana. Bandung: Yapemdo.

Sadiman, Arief S. (2009). Media Pendidikan Pengertian, Pengembangan Dan Pemanfaatannya. Jakarta: Rajawali Perss.

Wahyuni, Sri. (2016). Peningkatan Keterampilan Berbicara Bahasa Jawa Krama Alus Melalui Metode Bermain Peran Pada Siswa Kelas VIIID SMP Negeri 1 Baki Sukoharjo Tahun 2015/206. Skripsi. Surabaya: Universitas Widya Dharma.

Sudijono, Anas. (2005). Pengantar Statistik Pendidikan. Jakarta: PT Raja Grafindo Persada.

Suyanto, Slamet (2005). Dasar-Dasar Pendidikan Anak Usia Dini. Yogyakarta: Hikayat Publishing. 